\title{
STUDI TAKSONOMI BINTANG LAUT (Asteroidea, Echinodermata) DARI KEPULAUAN KARIMUNJAWA, JEPARA
}

\author{
Puspitasari, Suryanti, dan Ruswahyuni*)
}

Jurusan Perikanan, Fakultas Perikanan dan Ilmu Kelautan, Universitas Diponegoro Jl. Prof. H. Soedharto, SH, Tembalang Semarang. 50275 Telp/Fax (024) 7474698

\begin{abstract}
Abstrak
Bintang laut merupakan salah satu kelompok echinodermata yang berperan penting dalam jaring makanan, umumnya sebagai predator dan pemakan detritus. Penelitian ini dilaksanakan pada bulan Desember 2011 - Maret 2012. Penelitian ini bertujuan untuk mengetahui jenis, habitat dan ciri-ciri khusus bintang laut dari perairan Karimunjawa, Jepara. Pengambilan sampel dilakukan di kepulauan Karimunjawa, mencakup sisi barat dan timur pulau Karimunjawa, sisi barat pulau Menjangan Kecil, sisi utara pulau Cemara Kecil dan sisi utara pulau Cemara Besar, menggunakan metode purposive sampling. Sampel bintang laut dikumpulkan dari berbagai habitat di daerah intertidal sampai kedalaman 3 meter. Identifikasi setiap spesies dan pembuatan kunci identifikasi dilakukan di Pusat Penelitian Oseanografi (P2O-LIPI), Jakarta. Sebelas individu bintang laut dari 9 spesies yang mewakili 6 genera dari 4 famili dan 2 ordo berhasil di identifikasi. Sebagian besar bintang laut ditemukan di daerah terumbu karang. Berdasarkan karakter morfologi diketahui bahwa spesies yang tampaknya sama bahkan hidup di lokasi yang sama ternyata adalah spesies yang berbeda yaitu Archaster angulatus dan Archaster typicus, Nardoa frianti dan Nardoa pauciforis serta Linckia laevigata dan Linckia multifora. Semua jenis bintang laut yang dikumpulkan merupakan jenis-jenis yang umum ditemukan di perairan Indonesia.
\end{abstract}

Kata Kunci : Taksonomi, Identifikasi, Bintang Laut, Karimunjawa

\begin{abstract}
Sea stars play an important role in food webs, generally as predators and detritus feeder. This research has been conducted in December 2011 - March 2012. This research is subjected to achieved its biodiversity in the Karimunjawa Islands. Samples were collected from western and eastern side of Karimunjawa Island, western side of Menjangan Kecil, northern side of Cemara Kecil and northern side of Cemara Besar island, up to the depth of three meters. Species identification was done at Biology Laboratory of the Research Center for Oceanography (P2O-LIPI) Jakarta. A total of 11 asteroid individuals belonging to 9 species of 6 genera, which represented 4 families and 2 orders have been identified. Most of sea stars were found on the coral reef. Based on morphological characters of sea stars that apparently similar, even living in the same location, however after identified are different species, that is Archaster angulatus and Archaster typicus, Nardoa frianti and Nardoa pauciforis then Linckia laevigata and Linckia multifora. All species was considered common for tropical Indo Pasific region, including Indonesian waters
\end{abstract}

Keywords: Taxonomical, Identification, Asteroidea, Karimunjawa

\section{Pendahuluan}

Echinodermata merupakan biota yang penting penyusun komunitasnya. Jenis-jenis echinodermata tertentu dapat berpengaruh terhadap struktur dan komunitas terumbu karang melalui berbagai tingkat tropik dan lokasi geografis. Salah satu contohnya adalah bintang laut. Peningkatan kelimpahan jenis bintang laut tertentu dapat membawa perubahan besar dalam struktur komunitas terumbu karang (Darsono dan Aziz, 2002). Bintang laut merupakan salah satu taksa yang belum banyak diteliti di Indonesia, khususnya di perairan Karimunjawa, Jepara. Sepanjang penelusuran oleh Purwati dan Arbi (2012), dalam kurun waktu lebih dari 30 tahun terakhir hanya ada satu publikasi taksonomi bintang laut Indonesia yaitu dari perairan Anambas oleh Purwati dan Lane (2004). Menurut Moosa (1976), semua penelitian sumberdaya laut sangat tergantung pada identifikasi yang tepat dari suatu jenis. Pengetahuan dasar tentang jenis biota memegang peranan penting untuk mengetahui hubungan suatu jenis biota dengan ekosistemnya. Tanpa ${ }^{*)}$ Penulis Penanggung Jawab 
identifikasi, kita tidak dapat mengetahui bagaimana mencirikan suatu biota sehingga dapat menyulitkan upaya konservasi, budidaya, pengelolaan dan perlindungannya.

Indonesia memerlukan peneliti maupun mahasiswa yang mengerti dan pandai dalam identifikasi, karena koleksi spesimen merupakan world heritage (warisan dunia) dan bukti sejarah keberadaan kehidupan. Informasi mengenai jenis bintang laut dan habitatnya berguna dalam upaya pengelolaan serta menjaga kelestarian sumberdaya perikanan dan ekosistemnya. Tujuan dari penelitian ini adalah untuk mengetahui jenis, habitat setiap jenis dan untuk mengetahui ciriciri khusus bintang laut kepulauan karimunjawa, Jepara.

\title{
2. Materi dan Metode Penelitian
}

Bintang laut dikumpulkan dari pulau Karimunjawa, Cemara Kecil, Cemara Besar dan pulau Menjangan Kecil. Penelitian ini menggunakan metode deskriptif eksploratif. Metode pengambilan sampel menggunakan metode purposive sampling. Sampel bintang laut dikumpulkan dari 3 habitat yaitu rataan pasir, padang lamun dan terumbu karang. Sampel dikumpulkan terlebih dahulu sebelum diseleksi. Dasar pemilihan sampel adalah morfologi tubuh menurut Clark dan Rowe (1971). Sampel segar kemudian di foto, sebelum diawetkan dengan alkohol 70\%. Label dicantumkan disetiap individu bintang laut. Ukuran tubuh bintang laut diukur berdasarkan $\mathrm{R} / \mathrm{r}$, yaitu ratio panjang lengan $(R$, jarak dari tengah cakram sampai ujung lengan) dan jari-jari cakram ( $r$, jarak dari tengah cakram sampai tepi interradial). Identifikasi berdasarkan Clark dan Rowe (1971). Sinonim dan klasifikasi diambil dari literatur yang dicantumkan dalam penjelasan setiap spesies. Identifikasi, penulisan deskripsi, sinonim setiap spesies dan pembuatan kunci identifikasi bintang laut kepulauan Karimunjawa dilakukan di Pusat Penelitian Oseanografi LIPI (P2O-LIPI), Jakarta. Spesimen bintang laut Karimunjawa disimpan di ruang koleksi Pusat Penelitian Oseanografi (P2O-LIPI).

\section{Hasil dan Pembahasan}

\author{
FAMILI ARCHASTERIDAE VIGUIER, 1878 \\ Archaster angulatus Müller \& Troschel, 1842
}

(Gambar 1)

Archaster angulatus Müller \& Troschel, 1842: 66; Walenkamp, 1990: 31; Sukarno \& Jangoux, 1977: 830.

Spesimen -1 individu $(\mathrm{R} / \mathrm{r}=10,5 / 1,5 \mathrm{~cm}$; Pulau Cemara Besar, habitat pasir, $5 \mathrm{~cm})$.
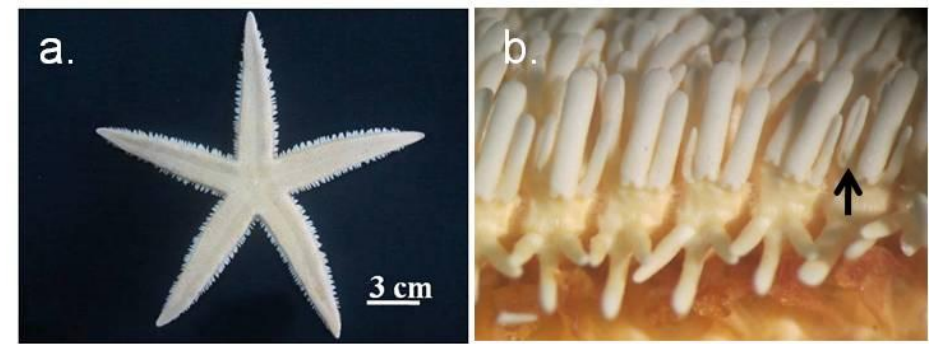

Gambar 1. Archaster angulatus: tampak dorsal (a); sisi ventral (b); pedicellaria berbentuk pinset (tanda panah).

Catatan - Spiniform pedicellaria terdapat di lempeng carinal, Pedicellaria berbentuk pinset terdapat di lempeng adambulacral juga dideskripsikan oleh Müller dan Troschel (1842) serta Sukarno dan Jangoux (1977).

\section{Archaster typicus Müller \& Troschel, 1840}

(Gambar. 2)

Archaster typicus Müller \& Troschel, 1840: 104; Müller \& Troschel, 1842: 65; Bedford, 1900: 271; Sukarno \& Jangoux, 1977: 822; Purwati \& Lane, 2004: 91 (sinonim lengkap).

Spesimen -1 individu $(\mathrm{R} / \mathrm{r}=7,5 / 1 \mathrm{~cm}$; Pulau Cemara Besar, habitat pasir, $5 \mathrm{~cm})$.

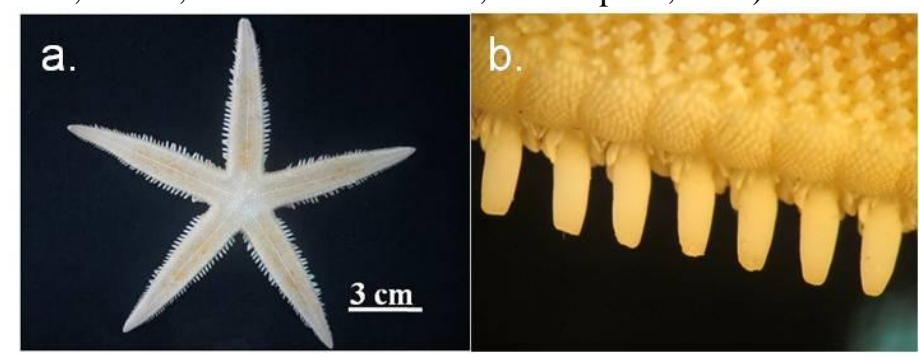

Gambar 2. Archaster typicus: tampak dorsal (a); duri inferomarginal (b). 
Catatan - Spesies ini sangat mirip dengan A. angulatus. Perbedaan yang menonjol dapat terlihat dari jumlah duri inferomarginal. A. typicus memiliki lempeng inferomarginal yang ditutupi oleh duri-duri pipih seperti sisik ikan. 1 duri pipih yang besar muncul dari setiap lempeng inferomarginal.

\section{FAMILI OPHIDIASTERIDAE VERRILL, 1867 \\ Linckia laevigata (Linnaeus, 1758) \\ (Gambar. 3)}

Asterias laevigata Linnaeus, 1758: 662; Lamarck, 1816: 566.

Linckia laevigata Clark, 1921: 64; Livingstone, 1932: 254; Clark, 1946: 117; Hayasaka, 1949: 16; Walenkamp, 1990: 58; Moosleitner, 1997: 10; Purwati \& Lane, 2004: 95.

Spesimen - 1 individu $(\mathrm{R} / \mathrm{r}=13 / 2,5 \mathrm{~cm}$; Pulau Cemara Kecil, habitat karang bercabang, $2 \mathrm{~m}) ; 1$ individu $(\mathrm{R} / \mathrm{r}=13,5 / 2$ cm; Pulau Menjangan Kecil, karang bercabang, 2 m).

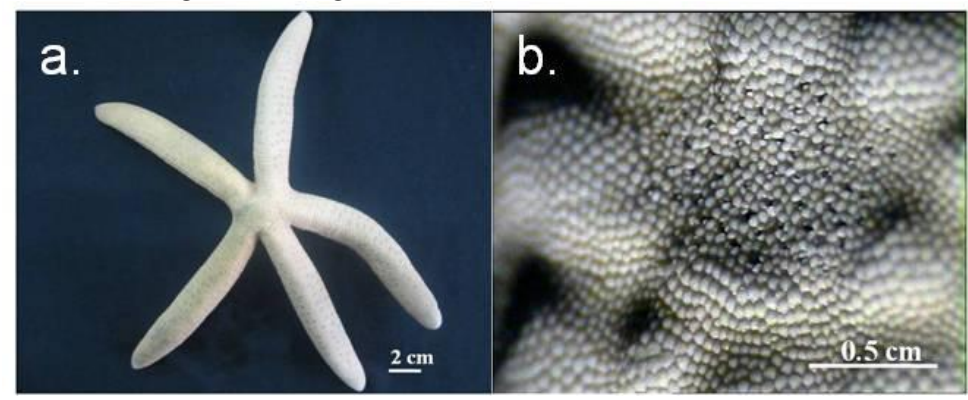

Gambar 3. Linckia laevigata: tampak dorsal (a); lempeng abactinal (b).

Catatan — L. laevigata memiliki 1 madreporit dengan ukuran lengan sama panjang, dan pori mengelompok.

\section{Linckia multifora (Lamarck, 1816)}

(Gambar. 4)

Asterias multifora Lamarck, 1816: 565.

Linckia multifora Marsh, 1974: 86; James, 1989: 102; Walenkamp, 1990: 61; Moosleitner, 1997: 10; Chao, 1999: 411; Rowe \& Richmond, 2004: 3285; Purwati \& Lane, 2004: 95.

Spesimen - 1 individu (R/r = 14/2 cm, Pulau Cemara Kecil, habitat karang bercabang, 2 m).

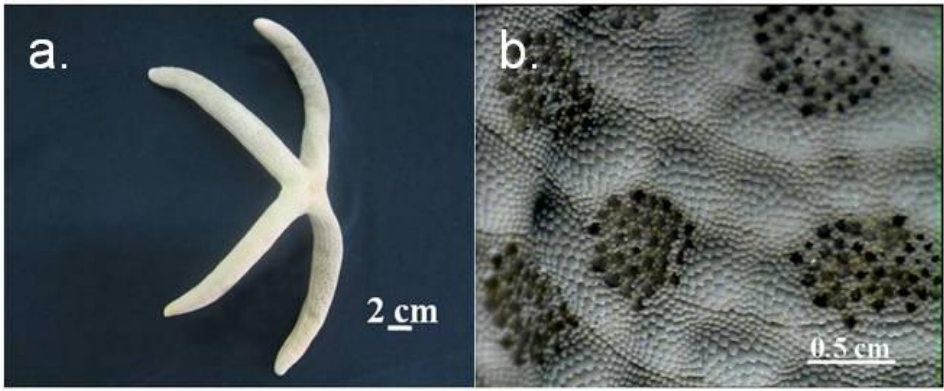

Gambar 4. Linckia multifora: tampak dorsal (a); lempeng abactinal (b).

Catatan - Spesies ini mirip dengan L. laevigata. Perbedaan yang menonjol terlihat dari jumlah madreporit dan ukuran lengan. L. multifora memiliki 2 madreporit dengan ukuran lengan yang tidak sama panjang dan lubang pori yang jelas terlihat.

\section{Nardoa frianti Koehler, 1910}

(Gambar. 5)

Nardoa frianti Koehler, 1910: 158; Clark, 1967: 175; Moosleitner, 1997: 10; Jeng, 1998: 142; Purwati \& Lane, 2004: 96; Chao \& Chang, 1989: 217 (sinonim lengkap);

Spesimen - 1 individu $(\mathrm{R} / \mathrm{r}=7,9 / 1,7 \mathrm{~cm}$, Pulau Karimunjawa, habitat karang, $2 \mathrm{~m})$; 1 individu $(\mathrm{R} / \mathrm{r}=8 / 2 \mathrm{~cm}$, Pulau Cemara Kecil, habitat karang bercabang, $2 \mathrm{~m}$ ). 


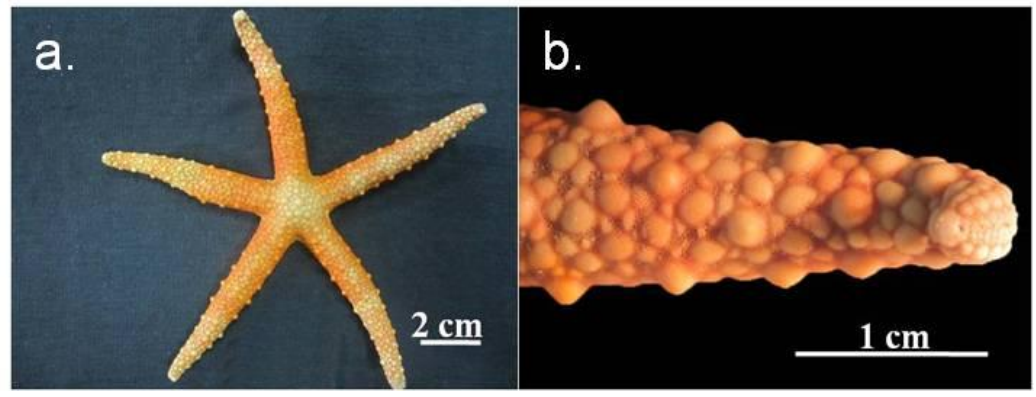

Gambar 5. Nardoa frianti: tampak dorsal (a); tuberkula di lengan (b).

Catatan - Kedua spesimen mempunyai cakram yang relatif cembung. Spesimen dengan ukuran $\mathrm{R} / \mathrm{r}=7,9 / 1,7 \mathrm{~cm}$ memiliki ujung tuberkula yang membulat sedangkan spesimen lain berukuran $\mathrm{R} / \mathrm{r}=8 / 2 \mathrm{~cm}$ memiliki ujung tuberkula yang relatif mengerucut.

\section{Nardoa pauciforis (Von Martens, 1866)}

(Gambar. 6)

Linckia pauciforis Von Martens, 1866: 69.

Nardoa pauciforis Clark, 1921: 51 (sinonim lengkap); Livingstone, 1932: 252; Clark, 1946: 115.

Spesimen -1 individu $(\mathrm{R} / \mathrm{r}=8,8 / 1,7 \mathrm{~cm}$, Pulau Karimunjawa, habitat karang, $2 \mathrm{~m})$.

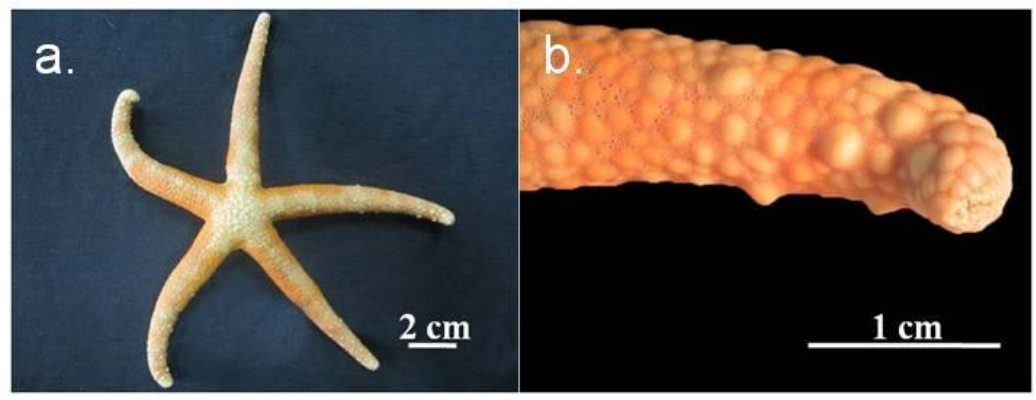

Gambar 6. Nardoa pauciforis: tampak dorsal (a); tuberkula di lengan (b).

Catatan - Spesies ini memiliki persamaan warna saat hidup dengan $N$. frianti, perbedaan yang menonjol adalah keberadaan tuberkula terbatas di bagian distal. Clark (1946), menyatakan bahwa tuberkula terletak di bagian distal lempeng abactinal, hal ini sesuai dengan spesimen yang hanya memiliki tuberkula di bagian distal.

\section{FAMILI OREASTERIDAE FISHER, 1911 \\ Culcita novaeguineae Müller \& Troschel, 1842}

(Gambar. 7)

Culcita novaeguineae Müller \& Troschel, 1842: 38; Bedford, 1900: 296; Clark, 1921: 32; Livingstone, 1932: 250; Clark, 1946: 108; Hayasaka, 1949: 14; Clark, 1954: 254; Marsh, 1974: 77; James, 1989: 100; Chao \& Chang, 1989: 216.

Spesimen — 1 individu (diameter $20 \mathrm{~cm}$, Pulau Menjangan Kecil, habitat karang, $3 \mathrm{~m}$ ).

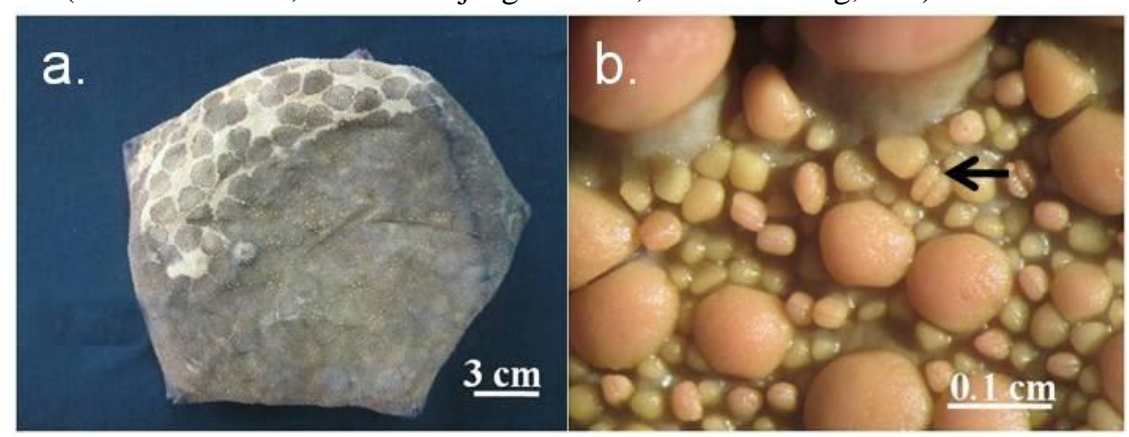

Gambar 7. Culcita novaeguineae: tampak dorsal (a); sisi ventral (b). pedicellaria berbentuk granula (tanda panah). 
Catatan — Bentuk tubuh seperti bantal (cushion-like). Pedicellaria berbentuk granula terdapat di sisi dorsal maupun ventral.

\section{Protoreaster nodosus (Linnaeus, 1758) \\ (Gambar. 8)}

Asterias nodosa Linnaeus, 1758: 661; Lamarck, 1816: 557

Oreaster nodosus Muller \& Troschel, 1842: 52; Clark, 1921: 31; Livingstone, 1932: 250.

Protoreaster nodosus Döderlein, 1936: 324; Clark, 1946: 106; Clark, 1954: 254.

Spesimen -1 individu $(\mathrm{R} / \mathrm{r}=16 / 9,5 \mathrm{~cm}$; Pulau Karimunjawa, habitat padang lamun, $10 \mathrm{~cm})$.

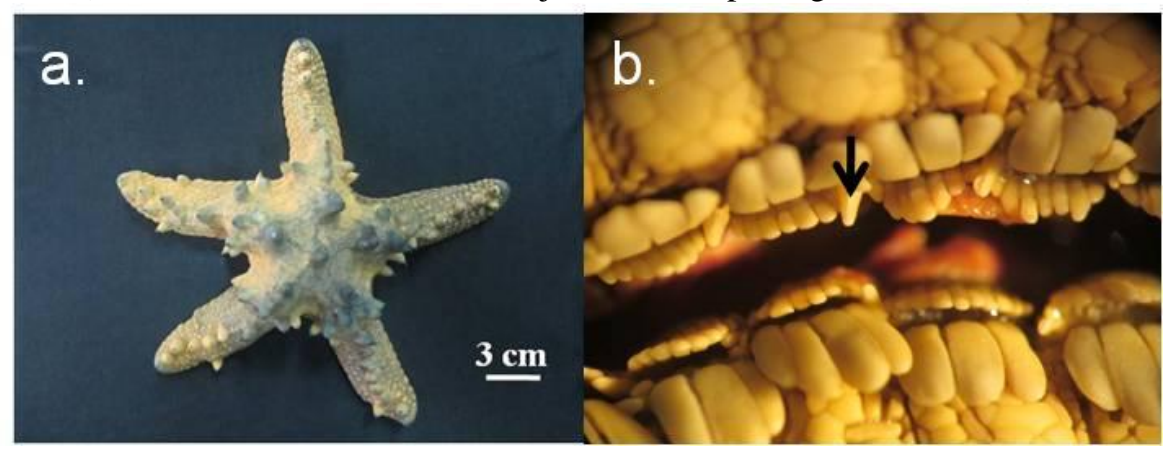

Gambar 8. Protoreaster nodosus: tampak dorsal (a); celah ambulacral (b); pedicellaria berbentuk pinset (tanda panah).

Catatan — Menurut Döderlein (1936), hanya disebutkan pedicellaria berbentuk lipatan yang terdapat di bagian ventrolateral, namun tidak menyebutkan pedicellaria berbentuk seperti pinset di samping duri-duri celah ambulacral.

\section{FAMILI ECHINASTERIDAE VERRILL, 1867 \\ Echinaster luzonicus Gray, 1840 \\ (Gambar. 9)}

Othilia luzonicus Gray, 1840: 282; Gray, 1841: 282.

Echinaster luzonicus Clark, 1921: 98; Livingstone, 1932: 263; Hayashi, 1940: 123; Clark, 1946: 146; Marsh, $1974: 93$ (sinonim lengkap); Jeng, 1998: 1425.

Spesimen -1 individu $(\mathrm{R} / \mathrm{r}=4 / 1 \mathrm{~cm}$; Pulau Karimunjawa, habitat padang lamun, $10 \mathrm{~cm})$.

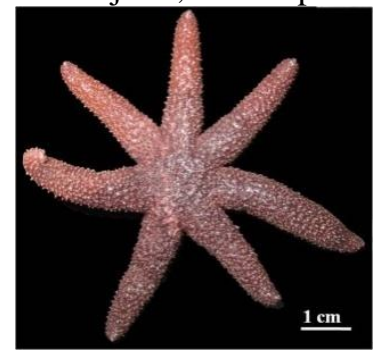

Gambar 9. Echinaster luzonicus: tampak dorsal

Catatan - Menurut Livingstone (1932), spesimen dengan 5, 6 dan 7 lengan memilliki 2 madreporit sedangkan pada spesimen yang berukuran relatif kecil $(\mathrm{R} / \mathrm{r}=4 / 1 \mathrm{~cm})$ dengan 7 lengan hanya memiliki 1 madreporit.

Kunci identifikasi bintang laut kepulauan Karimunjawa

1 Lempeng abactinal ditutupi paxilla, lengan pipih. Archaster. 2

1' Lempeng abactinal non-paxilla (granula atau lapisan kulit) .............................................................. 3

2 Setiap lempeng inferomarginal terdiri dari 1 duri pipih berbentuk seperti spatula.....Archaster typicus Müller dan Troschel, 1840

2' Setiap lempeng inferomarginal terdiri dari 1 - 3 duri pipih saling tumpang tindih ...Archaster angulatus Müller dan Troschel, 1842

3 Lempeng abactinal ditutupi oleh lapisan kulit. Echinaster luzonicus (Gray, 1840)

3' Lempeng abactinal ditutupi oleh granula

4 Area interradial lebar, bentuk tubuh massive 
4' Area interradial sempit.....

5 Lengan tidak berkembang, Pedicellaria berbentuk seperti granula di sisi dorsal dan ventral...Culcita novaeguineae Müller dan Troschel, 1842

5' Lengan besar, Bivalve pedicellaria di sisi ventral. Diantara duri celah ambulacral terdapat pedicellaria seperti

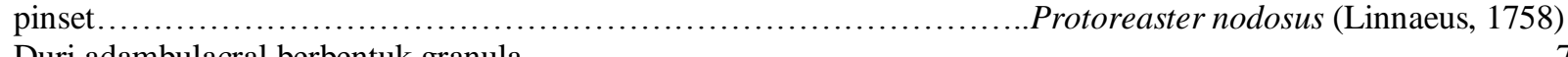

6 Duri adambulacral berbentuk granula

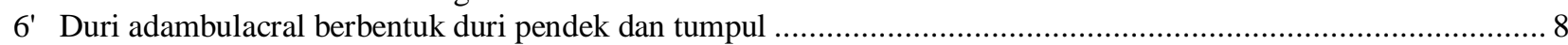

7 Madreporit tunggal, lengan sama panjang..................................................... Linckia laevigata (Linnaeus, 1758)

7' Madreporit ganda, lengan tidak sama panjang.............................Linckia multifora (Lamarck, 1816)

8 Tuberkula terdapat di sepanjang lengan...................................Nardoa frianti Koehler, 1910

8' Tuberkula terbatas di bagian distal.......................................Nardoa pauciforis (Von Martens, 1866)

Sebagian besar bintang laut yang dikumpulkan seperti L. laevigata, L. multifora, N. frianti, N. pauciforis dan C. novaeguineae ditemukan hidup di daerah terumbu karang. Menurut Sloan (1980), genus Linckia dan Nardoa hidup dari mukus yang dihasilkan oleh hewan karang sedangkan C. novaeguineae memakan polip karang dan spons. A. typicus dan A. angulatus ditemukan di daerah berpasir. P. nodosus dan E. luzonicus ditemukan di daerah padang lamun. Menurut Sloan (1980), P. nodosus hidup dari alga yang menempel pada daun lamun yang telah membusuk sedangkan Echinaster termasuk scavenger serta pemakan plankton dan seston. Berdasarkan hasil penelitian yang diperkuat oleh Birkeland (1989) dan Sloan (1980), bintang laut memiliki kesukaan habitat (prefered habitat) yang dipengaruhi oleh cara makan dan macam makanannya.

Secara ekologis, bintang laut berperan dalam ekosistem terumbu karang, umumnya sebagai pemakan detritus dan predator (Birkeland, 1989). C. novaeguineae merupakan pemangsa karang. Menurut Sloan (1980), C. novaeguineae tidak dianggap sebagai ancaman utama terhadap terumbu karang seperti Acanthaster planci. Sebagian besar bintang laut Karimunjawa termasuk pemakan detritus yaitu L. laevigata, L. multifora, A. angulatus, A. typicus, N. frianti, $N$. pauciforis, $P$. nodosus dan E. luzonicus. Hewan pemakan detritus berperan dalam mendaur ulang detritus serta mengembalikannya kedalam rantai makanan. Berdasarkan hasil penelitian terdapat empat spesies yang belum pernah terdata ada di perairan kepulauan Karimunjawa yaitu L. multifora, A. angulatus, $N$. frianti dan N. pauciforis. Hal ini diperkuat oleh Aziz dan Darsono (1999) dan BTNKj (2008) yang tidak menyebutkan adanya keempat spesies tersebut. Informasi mengenai bintang laut yang belum pernah terdata sebelumnya, menandakan bahwa masih dibutuhkan penelitian lebih lanjut tentang keanekaragaman bintang laut di kepulauan Karimunjawa.

\section{Kesimpulan}

Berdasarkan hasil penelitian di kepulauan Karimunjawa ditemukan 9 spesies bintang laut yang mewakili 6 genera dari 4 famili dan 2 ordo yaitu Linckia laevigata, Linckia multifora, Nardoa frianti, Nardoa pauciforis Culcita novaeguineae, Archaster typicus, Archaster angulatus, Protoreaster nodosus dan Echinaster luzonicus. Lima jenis bintang laut ditemukan di daerah terumbu karang, dua jenis ditemukan di daerah padang lamun dan dua jenis lainnya ditemukan di daerah berpasir. Setiap spesies memiliki ciri-ciri khusus yang dapat digunakan untuk menentukan spesies bintang laut.

\section{Ucapan Terima Kasih}

Ucapan terima kasih disampaikan kepada Dra. Pradina Purwati, MSc. di Pusat Penelitian Oseanografi LIPI, Jakarta yang telah membantu dalam proses identifikasi dan penulisan taksonomi bintang laut kepulauan Karimunjawa.

\section{Daftar Pustaka}

Aziz, A dan P. Darsono. 1999. Fauna Echinodermata dari Pulau-pulau Karimunjawa, Jepara. Majalah Ilmu Kelautan UNDIP, 14:83-92.

Balai Taman Nasional Karimunjawa (BTNKj). 2008. Statistik Balai Taman Nasional Karimunjawa. Departemen Kehutanan DITJEN PHKA. Semarang.

Birkeland, C. 1989. The Influence of Echinoderms on Coral Reefs Communities. Dalam: A. Aziz. Makanan dan Cara Makan Berbagai Jenis Bintang Laut. Oseana, 21(3):13-22.

Bedford, F. P. 1900. On the Echinoderms from Singapore and Malacca. Proceedings of the Zoological Society of London, 14:271-299.

Chao, S. M. 1999. Revision of Taiwan Starfish (Echinodermata: Asteroidea), with Description of Ten New Records. Zoological Studies 38(4):405 - 415.

Chao, S. M and K. H. Chang. 1989. Some Shallow Water Asteroids (Echinodermata: Asteroidea) from Taiwan. Bulletin of the Institute Zoology, Academia Sinica, 28(3):215-223.

Clark, A. H. 1954. Records of Indo-Pacific Echinoderms. Pacific Science, 8:243-263.

Clark, A. M. 1967. Notes on Asteroids in the British Museum (Natural History) V. Nardoa and Some Other Ophidiasterids. Bulletin British Museum National Hist. Zool, 15:169-198.

Clark, A. M and F. W. E. Rowe. 1971. Monograph of Shallow-Water Indo-West Pasific Echinoderms. Trustees of the British Mus. (Nat. His.), London, 238 p. 
Clark, H. L. 1921. The Echinoderm Fauna of the Torres Strait: Its Composition and Its Origin. Carnegie Institute of Washington, 10:223p.

Clark, H. L. 1946. The Echinoderm Fauna of Australia: Its Composition and Its Origin. Carnegie Institute of Washington, 64-161.

Darsono, P dan A. Aziz. 2002. Komunitas Echinodermata dari Beberapa Pulau di Daerah Sulawesi Utara. Majalah Ilmu Kelautan UNDIP, 26(7):77-88.

Döderlein, L. 1936. Die Unterfamilie Oreasterinae. Siboga Expeditie. G. J. Brill, Leiden, 46c:295-368.

Gray, J. E. 1841. A Synopsis of the Genera and Species of the Class Hypostoma (Asterias, Linnaeus). The Annals and Magazines of Natural History Zoology, Botany and Geology, 6(22):175-184.

Hayasaka, I. 1949. On Some Starfishes from Taiwan. Bulletin of the Oceanogaphical Institute of Taiwan, 5:11 - 19.

Hayashi, R. 1940. Contributions to the Classification of the Sea-stars of Japan : I. Spinulosa. Journal of The Faculty of Science Hokkaido Imperial Series VI. Zoology, 7(3):107-204.

James, D. B. 1989. Echinoderms of Lakshadweep and Their Zoogeography. Bulletin of Marine Living Resources of the Union Territory of Lakshadweep, 23:97-143.

Jeng, M. S. 1998. Shallow Water Echinoderms of Taiping Island in the South China Sea. Zoological Studies, $37(2): 137-$ 153.

Lamarck, M. C. de. 1816. Histoire Naturelle des Animaux sans Vertebras, 2(1) Les Stellérides. Tome Second, Paris, $568 \mathrm{p}$.

Linnaeus, C. 1758. Systema Naturae. Impensis Direct, Holmiae, 10, 824p.

Livingstone, A. A. 1932. Asteroidea: Scientific Report of the Great Barrier Reef Expedition, 4:241-265.

Marsh, L. M. 1974. Shallow-Water Asterozoans of Southeastern Polynesia: I. Asteroidea. Micronesia, 10(1):65-104.

Moosa, M. K. 1976. Pentingnya Pengetahuan Tentang Identitas Suatu Jenis. Oseana, 5:1-3.

Moosleitner, H. 1997. Shallow Water Asteroidea (Echinodermata) from the Coral Reefs of the Maldive Islands. Revue Française d'Aquariologie et Herpetologie, 24:3-14.

Müller, J. and F. H. Troschel. 1842. System der Asteriden. Braunschweig, 134 p.

Purwati, P and D. J. W. Lane. 2004. Asteroidea of the Anambas Expedition 2002. The Raffles Bulletin of Zoology, 11:89-102.

Purwati, P dan Arbi, U. Y. 2012. Karakter Morfologi Bintang Laut Untuk Identifikasi. Oseana, 37(1): 1 - 9.

Rowe F. W. E and M. D. Richmond. 2004. A Preliminary Account of the Shallow-water Echinoderms of Rodrigues, Mauritius, Western Indian Ocean. Journal of Nat. Hist., 38:3273-3314.

Sloan, N.A. 1980. Aspect of The Feeding Biology of Asteroids. Oceanogr. Mar. Biol. Ann. Rev., 18:57-124.

Sukarno, P and M. Jangoux. 1977. Revision du genre Archaster Muller et Troschel (Echinodermata, Asteroidea: Archasteridae). Revue de Zoologie et de Botanique Africaines, 91(4):817-844, pl. 4-6.

Walenkamp, J. H. C. 1990. Systematics and Zoogeography of Asteroidea (Echinodermata) from Inhaca Island, Mozambique. National Natuurhistorisch Museum, Leiden, 1-86. 